\title{
Early colonizing Escherichia coli elicits remodeling of rat colonic epithelium shifting toward a new homeostatic state
}

\author{
Julie Tomas ${ }^{1,2,3}$, Julie Reygner ${ }^{4,5}$, Camille Mayeur ${ }^{1,2,3}$, Robert Ducroc $^{6}$, Stephan Bouet ${ }^{7,8,9}$, \\ Chantal Bridonneau ${ }^{1,2,3}$, Jean-Baptiste Cavin ${ }^{6}$, Muriel Thomas ${ }^{1,2,3}$, Philippe Langella ${ }^{1,2,3}$ \\ and Claire Cherbuy ${ }^{1,2,3}$ \\ ${ }^{1}$ INRA, UMR 1319 MICALIS, F-78350, Jouy-en-Josas, France; ${ }^{2}$ AgroParisTech, UMR 1319 MICALIS, F-78350, \\ Jouy-en-Josas, France; ${ }^{3}$ Commensal and Probiotics-Host Interactions Laboratory, INRA, UMR 1319 MICALIS, \\ F-78350, Jouy-en-Josas, France; ${ }^{4}$ PERITOX, EA 4285 UMI 01 INERIS, UFR of Medecine-UPJV, Amiens, France; \\ ${ }^{5}$ EGEAL team, UPSP 2007-05-137, Institut Polytechnique La Salle Beauvais, Beauvais, France; ${ }^{6}$ Inserm \\ UMRS1149, UFR de Médecine Paris 7, Université Paris Diderot, Sorbonne Paris Cité, Paris, France; ${ }^{7}$ INRA, \\ UMR 1313, Animal Genetics and Integrative Biology, F-78350, Jouy-en-Josas, France; ${ }^{8}$ Laboratory of \\ Radiobiology and Genomics Studies, CEA, DSV, IRCM, SREIT, F-78350, Jouy-en-Josas, France and \\ ${ }^{9}$ AgroParisTech, UMR 1313, Animal Genetics and Integrative Biology, F-78350, Jouy-en-Josas, France
}

\begin{abstract}
We investigated the effects of early colonizing bacteria on the colonic epithelium. We isolated dominant bacteria, Escherichia coli, Enterococcus faecalis, Lactobacillus intestinalis, Clostridium innocuum and a novel Fusobacterium spp., from the intestinal contents of conventional suckling rats and transferred them in different combinations into germfree (GF) adult rats. Animals were investigated after various times up to 21 days. Proliferative cell markers (Ki67, proliferating cell nuclear antigen, phospho-histone $\mathrm{H} 3$, cyclin A) were higher in rats monocolonized with $E$. coli than in GF at all time points, but not in rats monocolonized with $E$. faecalis. The mucin content of goblet cells declined shortly after $E$. coli administration whereas the mucus layer doubled in thickness. Fluorescence in situ hybridization analyses revealed that $E$. coli resides in this mucus layer. The epithelial mucin content progressively returned to baseline, following an increase in KLF4 and in the cell cycle arrest-related proteins p21 ${ }^{\mathrm{CIP} 1}$ and $\mathrm{p} 27^{\mathrm{KIP} 1}$. Markers of colonic differentiated cells involved in electrolyte (carbonic anhydrase II and s/c26A3) and water (aquaglyceroporin3 (aqp3)) transport, and secretory responses to carbachol were modulated after $E$. coli inoculation suggesting that ion transport dynamics were also affected. The colonic responses to simplified microbiotas differed substantially according to whether or not $E$. coli was combined with the other four bacteria. Thus, proliferation markers increased substantially when $E$. coli was in the mix, but very much less when it was absent. This work demonstrates that a pioneer strain of $E$. coli elicits sequential epithelial remodeling affecting the structure, mucus layer and ionic movements and suggests this can result in a microbiota-compliant state.
\end{abstract}

The ISME Journal (2015) 9, 46-58; doi:10.1038/ismej.2014.111; published online 11 July 2014

\section{Introduction}

Throughout life, the mammalian gut is engaged in dynamic interactions with a vast microbial community in conditions that should allow homeostasis (Brown et al., 2013). Associations with the gut microbiota develop following every birth, as the newborn passes from a protected site to a densely colonized environment. The microbiota that colonizes first depends on the mode of delivery (DominguezBello et al., 2010). The human gut microbiota

Correspondence: C Cherbuy, INRA, MICALIS (UMR 1319), Domaine de Vilvert, F-78350, Jouy-en-Josas, France.

E-mail: claire.cherbuy@jouy.inra.fr

Received 5 November 2013; revised 23 May 2014; accepted 28 May 2014; published online 11 July 2014 evolves substantially over the first years of life and is formed by the successive emergence of diverse bacterial groups: aerotolerant bacteria establish first and strict anaerobes later (Palmer et al., 2007; Adlerberth and Wold, 2009). Following weaning, the gut microbial community then converges toward that found in the adult intestine (Yatsunenko et al., 2012). The microbiota in infants conforms to the particular characteristics of the postnatal period, and displays functions different from those found in adults (Koenig et al., 2011; Yatsunenko et al., 2012). Experimental studies have documented the contributions of these first colonizing microbes to health. Indeed, in mice, the bacterial status, and the antibiotic exposure, early in life may have long-lasting consequences for susceptibility to immune-mediated diseases (Olszak et al., 2012; Russell et al., 2012). 
The first cells that are confronted by this microbial consortium are intestinal epithelial cells, mainly in the colon where the bacterial density is the highest. The colonic epithelium is composed of tightly attached cells including columnar, goblet and enteroendocrine cells as differentiated epithelial lineages. These cells are continuously renewed by proliferation at the crypt base and terminal differentiation at the luminal surface (Van der Flier and Clevers, 2009). The epithelium displays various properties that sustain the complex and dynamic microbial communities of the gut. They include mucus secretion by goblet cells and the production of antimicrobial peptides (Hooper and Macpherson, 2010). A recent modeling approach predicted that these epithelial secretions act as a selective force providing competitive advantages to commensal intestinal bacteria that would otherwise be lost (Schluter and Foster, 2012). There is also evidence that the transport of ions and fluid, the primary physiological function of intestinal epithelial cells, can also have a role in commensal bacteria-host cell interactions (Keely et al., 2012).

We investigated the responses of the colonic epithelium to early colonizing bacteria. We isolated dominant bacteria (Escherichia coli, Enterococcus faecalis, Lactobacillus intestinalis, Clostridium innocuum and a novel Fusobacterium spp.) from 15-dayold conventional (CV) suckling rats and the effects of these bacteria were tested over 21 days in growing adult gnotobiotic rats. This model, and not neonatal rats, was used because of the delay in the gastrointestinal tract maturation in rodents relative to humans in which the intestinal epithelium is mature at birth (Puiman and Stoll, 2008; Drozdowski et al., 2010). We performed a kinetic study as colonic responses are progressive after the transfer of a complex microbiota into germfree (GF) animals (Cherbuy et al., 2010; El Aidy et al., 2012; Tomas et al., 2013). The time points used correspond to before the total renewal of the colonic epithelium (3 days) and after one (7 days) or several (21 days) renewals of the colonic epithelium.

We report the prominent role of $E$. coli relative to other early colonizers isolated and insights into the involvement of the epithelial responses in the dynamics of homeostatic host-microbe interactions. We show that administration of E. coli elicits sequential remodeling of the colonic epithelium affecting the dynamics of proliferation, of mucus production and of ionic movements. These effects may contribute to a favorable microenvironment for commensal colonization.

\section{Materials and methods}

Selection of bacterial species

Freshly collected intestinal contents from six 15-day-old CV suckling rats were pooled, plated on selective media (desoxycholate citrate agar, bile esculin agar, MRS and brain heart infusion supplemented with $0.5 \mathrm{mg} \mathrm{ml}^{-1}$ cysteine), and cultured overnight aerobically and anaerobically for the isolation of Enterobacteriaceae, Enterococcus, Lactobacillus and anaerobic bacteria (Supplementary Figure S1). One colony per plate was picked and grown in appropriate liquid media to obtain the starting stocks, which were kept at $-80^{\circ} \mathrm{C}$. The representativeness of each isolated group for the intestinal contents of suckling rats was assessed by PCR-temporal temperature gradient gel electrophoresis (TTGE) (Supplementary Figure S2).

\section{Identification of bacterial species}

Bacterial species were identified by analyses of the DNA sequence of the 16S rRNA gene. DNA was extracted from each bacterial culture as in (Tomas et al., 2013). Primers GCclamp-U968 (GCclamp-5'-GAACGCGAAGAACCTTAC-3') and L1401 (5'-GCGTGTGTACAAGACCC-3') were used to amplify the V6-V8 regions of bacterial 16S rRNA genes (Gerard et al., 2004). PCR products were purified using the Promega Wizard SV PCR clean-up system (Promega, Lyon, France) and sequenced by Eurofins MGW Operon (Ebersberg, Germany). Results of tests performed for isolated bacterial characterization are given in Supplementary Table S1. E. coli, E. faecalis, L. intestinalis, C. innocuum and the novel Fusobacterium spp. were identified and the strains were named CEC15, CEF15, CLI15, CCI15 and CFV15, respectively.

\section{Bacterial culture conditions}

Bacterial cultures were prepared separately from aliquots stored at $-80^{\circ} \mathrm{C}$ and cultured overnight at $37^{\circ} \mathrm{C}$ : E. coli, E. faecalis and L. intestinalis were grown in aerobic conditions in LB and MRS media, respectively; C. innocuum and the novel Fusobacterium spp. were cultured in anaerobic condition in LYHBHI with $0.5 \%$ yeast extract, $5 \mathrm{mgl}^{-1}$ of hemin and $0.5 \mathrm{mg} \mathrm{ml}^{-1}$ cysteine.

\section{Gnotobiotic rats}

All procedures were carried out according to European guidelines for the care and the use of laboratory animals with permission A78-196 from the French Veterinary Services. Animal experiments were evaluated and approved by the local ethics committee. Rats (males, Fisher 344) were bred at INRA gnotobiotic facilities (Jouy-en-Josas, France) as described in (Cherbuy et al., 2010). Six groups of gnotobiotic rats were studied (Supplementary Table S2): GF rats, two groups of monoxenic rats inoculated with either E. coli CEC15 or E. faecalis CEF15 (Monocoli and Monofaecalis groups, respectively), one group of dixenic rats inoculated with $E$. coli CEC15 and E. faecalis CEF15 (Dicolifaecalis group), and two more complex gnotobiotic groups, inoculated with E. faecalis CEF15, L. intestinalis CLI15, 
C. innocuum CCI15 and the novel Fusobacterium spp. CFV15 with (EELCF group) or without (ELCF group) E. coli CEC15 (Supplementary Table S2). CV rats were also used as complex microbiota control.

Inocula were prepared as follows: fresh overnight cultures were centrifuged at $4{ }^{\circ} \mathrm{C}$ for $20 \mathrm{~min}$ at 12000 r.p.m., resuspended in LB medium and immediately introduced into the isolator. For mixed inoculations, bacterial strains were cultured separately, $1 \mathrm{ml}$ aliquots were pooled, centrifuged and resuspended in $1 \mathrm{ml}$ of LB medium. In all cases, GF rats were inoculated once by oral gavage with $1 \mathrm{ml}$ of bacterial suspension. The samples used for the inoculation contained $10^{9}$ c.f.u. $\mathrm{ml}^{-1}$. Monocoli, Monofaecalis and Dicolifaecalis groups were killed 3, 7 or 21 days post inoculation. EELCF and ELCF groups were killed 3 or 21 days post inoculation. Each experiment was carried out independently at least three times. The rats used for these experiments were aged between 9 weeks and 12 weeks such that all rats were killed at the age of 3 months. Fisher 344 rats are in the growth phase at this age (Turturro et al., 1999). Rats were anesthetized with isoflurane, the colons recovered and immediately used for cell isolation, histological procedures or permeability measurement in an Ussing chamber (Easy Mount, Physiologic Instruments, San Diego, CA, USA). Cecal contents were immediately frozen at $-80^{\circ} \mathrm{C}$ for bacterial enumeration.

\section{E. coli and E. faecalis quantification}

Bacteria in cecal contents were quantified by realtime quantitative PCR analyses targeting bacterial group-specific 16S rRNA genes as in (Tomas et al., 2013).

Colonic epithelial cell isolation, and protein and RNA extraction

Colonic epithelial cells were isolated from the whole colon according to (Cherbuy et al., 1995). Protein and RNA were extracted from colonic epithelial cells as in (Rul et al., 2011). RNA quality was checked by R6K ScreenTape analyses (Agilent Technologies, Santa Clara, CA, USA) with an average RNA integrity number of 8 on a scale of $0-10$.

\section{Western blot analyses}

Western blot (WB) analyses were performed as in (Thomas et al., 2011). Signals on autoradiographic films were quantified by scanning densitometry with Biovision 1000 and Bio-1D software (Vilber Lourmat, Marne-la-Vallée, France).

\section{Real-time quantitative PCR analyses of colonic} epithelial gene expression

Colonic epithelial RNAs were analyzed by real-time quantitative PCR. Assays designed by Applied Biosytems (respectively Rn00709709-m1 and Rn00581754-m1) were used for the detection of slc26A3 and aquaglyceroporin3 (aqp3) as in (Tomas et al., 2013). Differences were calculated using the comparative 2- $\Delta \Delta \mathrm{Ct}$ method (Livak and Schmittgen, 2001). Results obtained with the 7000 system software version 1.2.3 (Applied Biosytems) were normalized to those for the 18S rRNA gene (Hs99999901-s1) and compared with the mean target gene expression in GF rats.

Histology, immunostaining and in situ hybridization Flushed colons were fixed in $4 \%$ paraformaldehyde, dehydrated and embedded in paraffin according to a standard protocol. Histological features were analyzed by hematoxylin-eosin-safran staining. Periodic acid-Schiff (PAS) and Alcian blue (AB) staining were performed as in (Wrzosek et al., 2013). The EnVision + System-HRP (DakoCytomation, Trappes, France) was used for immunohistochemistry and nuclei counterstained with Mayer's hematoxylin. In immunofluorescence (IF) experiments, fluorescence-labeled secondary antibodies were used and nuclei stained with Hoechst. Antigen retrieval was performed in buffer $\mathrm{pH} 6.0$ or pH 9.0 (EnVision FLEX Target Retrieval Solution, DakoCytomation) for $40 \mathrm{~min}$ at $97^{\circ} \mathrm{C}$. The RNAscope kit (ACD, Hayward, CA, USA) was used according to the supplier's instructions for in situ hybridization. Probes were targeted in the 458-1795 Wnt5a mRNA region of the Rattus norvegicus (NM_022631.1).

\section{Antibodies}

The following primary antibodies were used: antiKi67 (DakoCytomation); anti-proliferating cell nuclear antigen (PCNA) (GeneTex, Irving, CA, USA), antiKLF4 and anti-phospho-histone H3 (PH3) (Abcam, Cambridge, MA, USA); anti-cyclin A, anti-p21 ${ }^{\mathrm{CIP} 1}$, anti-p27 ${ }^{\mathrm{KIP}}$, anti-MUC2, anti-Bax, anti-carbonic anhydrase II (CAII) (Santa Cruz Biotechnology, Dallas, TX, USA); anti-ZO-1, anti-claudin-1, anti-occludin (Invitrogen, Saint Aubin, France). Anti-SKP1 (BD Transduction, Rungis, France) was used as the loading control in WB experiments.

\section{Mucus thickness analyses and fluorescence in situ hybridization assays}

Unwashed colons were gently bound in situ, coated with optimum cutting temperature compound and frozen in liquid nitrogen. Frozen sections were cut and slides placed in water-free Carnoy's fixative before IF assay with the anti-MUC2 antibody as described above. DNA was stained with Hoechst revealing both eukaryotic and bacterial cells. To complete Hoechst observation of bacteria, fluorescence in situ hybridization (FISH) experiments were performed. FISH for detection of E. coli CEC15 was unsatisfactory with slides from unwashed colon fixed in Carnoy's fixative. Therefore, slides were fixed in $4 \%$ paraformaldehyde and then hybridized with $4 \mathrm{ng}_{\mu \mathrm{l}}^{-1}$ of the general bacterial probe Eub338 as described in (Rochet et al., 2004). 
Image acquisition and analyses

Crypt depth, PAS-, AB-, Ki67-, PCNA- and PH3positive cells were scored using NanozoomerDigitalPathology.view software (Hamamatsu Photonics, Hamamatsu, Japan) as described in (Cherbuy et al., 2010). Structured illumination microscopy was used to observe fluorescent signals and for photography (Zeiss Apotome, Oberkochen, Germany). The intensity of MUC2 staining and the thickness of the mucus layer were evaluated with MacBiophotonics ImageJ software.

Tissue conductance and permeability measurements Pieces of colon $\left(0.5 \mathrm{~cm}^{2}\right)$ were mounted in Ussing chambers as previously described (Ducroc et al., 1988). Electrogenic ion transport was monitored as short-circuit current (Isc) using an
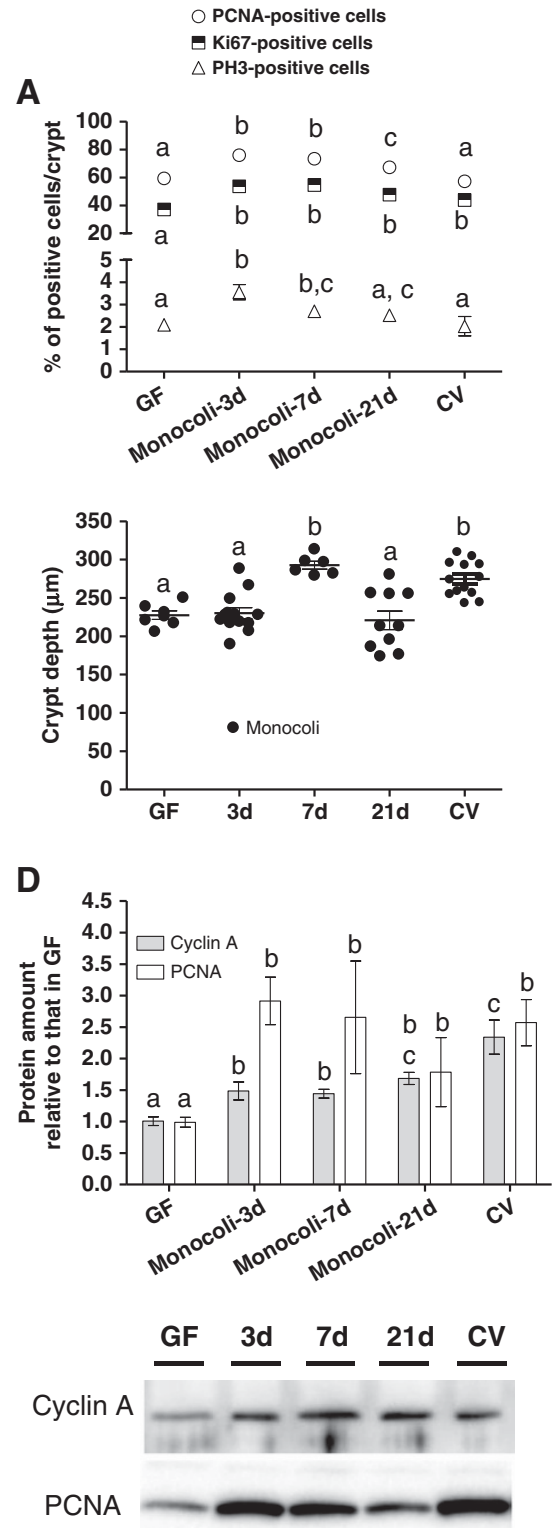

SKP1
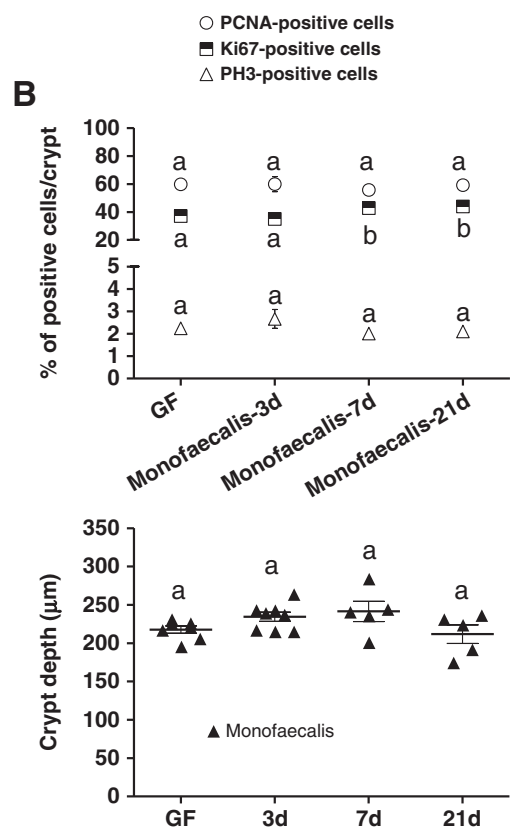

E
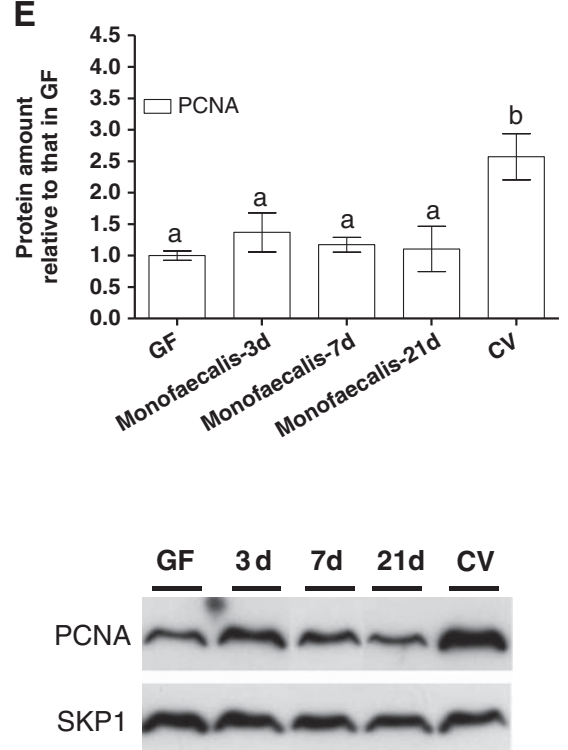

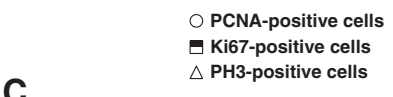

C
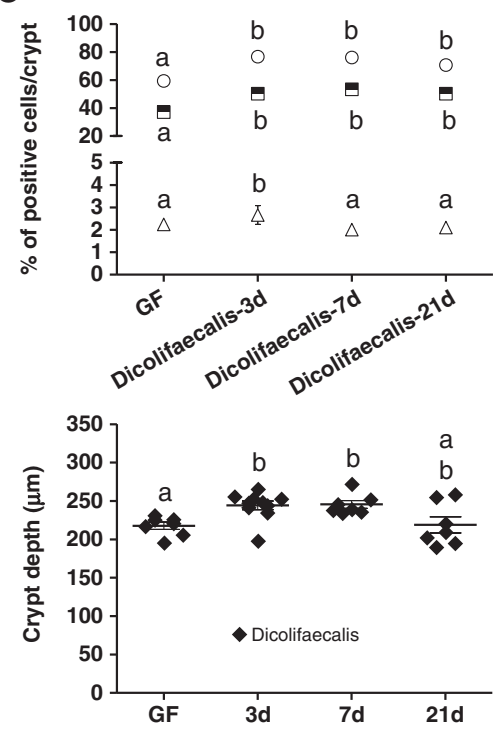

F
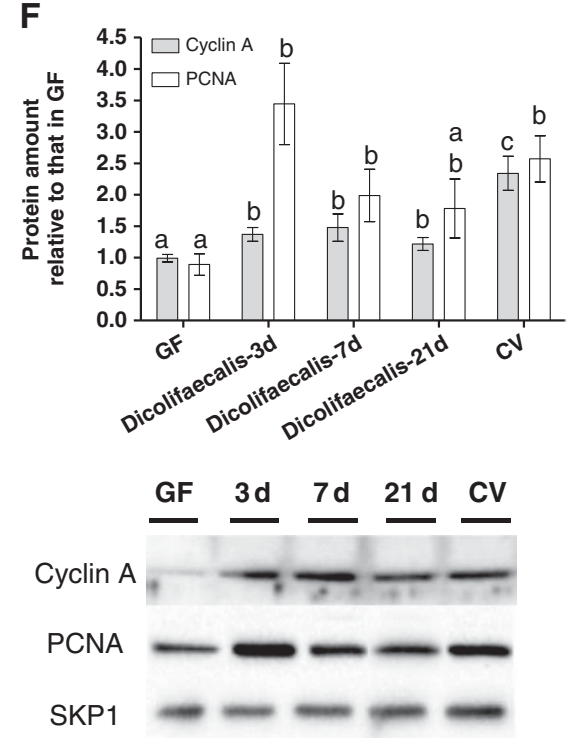

Figure 1 Histological and proliferation marker analyses of the colonic epithelium from gnotobiotic rats inoculated either with Escherichia coli CEC15 (Monocoli group) or with Enterococcus faecalis CEF15 (Monofaecalis group) or both (Dicolifaecalis group). (A-C) Percentages of PCNA-, Ki67- and PH3-positive cells/crypt and colonic crypt depth measurement on colonic sections from (A) the Monocoli group ( $n=6-13)$, (B) the Monofaecalis group $(n=7-8)$ and (C) the Dicolifaecalis group $(n=7-11)$. Inoculated rats were killed 3, 7 and 21 days post inoculation. GF and CV rats were used as controls $(n=7-13)$. Representative photographs of Ki67 immunohistochemistry are shown in Supplementary Figure S3. (D-F) Western blot analyses of proliferative markers on isolated colonic epithelial cells in (D) Monocoli group ( $n=6-13)$, (E) Monofaecalis group ( $n=7$ to 8) and (F) Dicolifaecalis group ( $n=7-11)$. Graphs show densitometric analyses of cyclin A and PCNA signals with a representative western blot image. SKP1 was used as a loading control. The mean values with letter designations are significantly different $(P$-value $<0.05)$. 

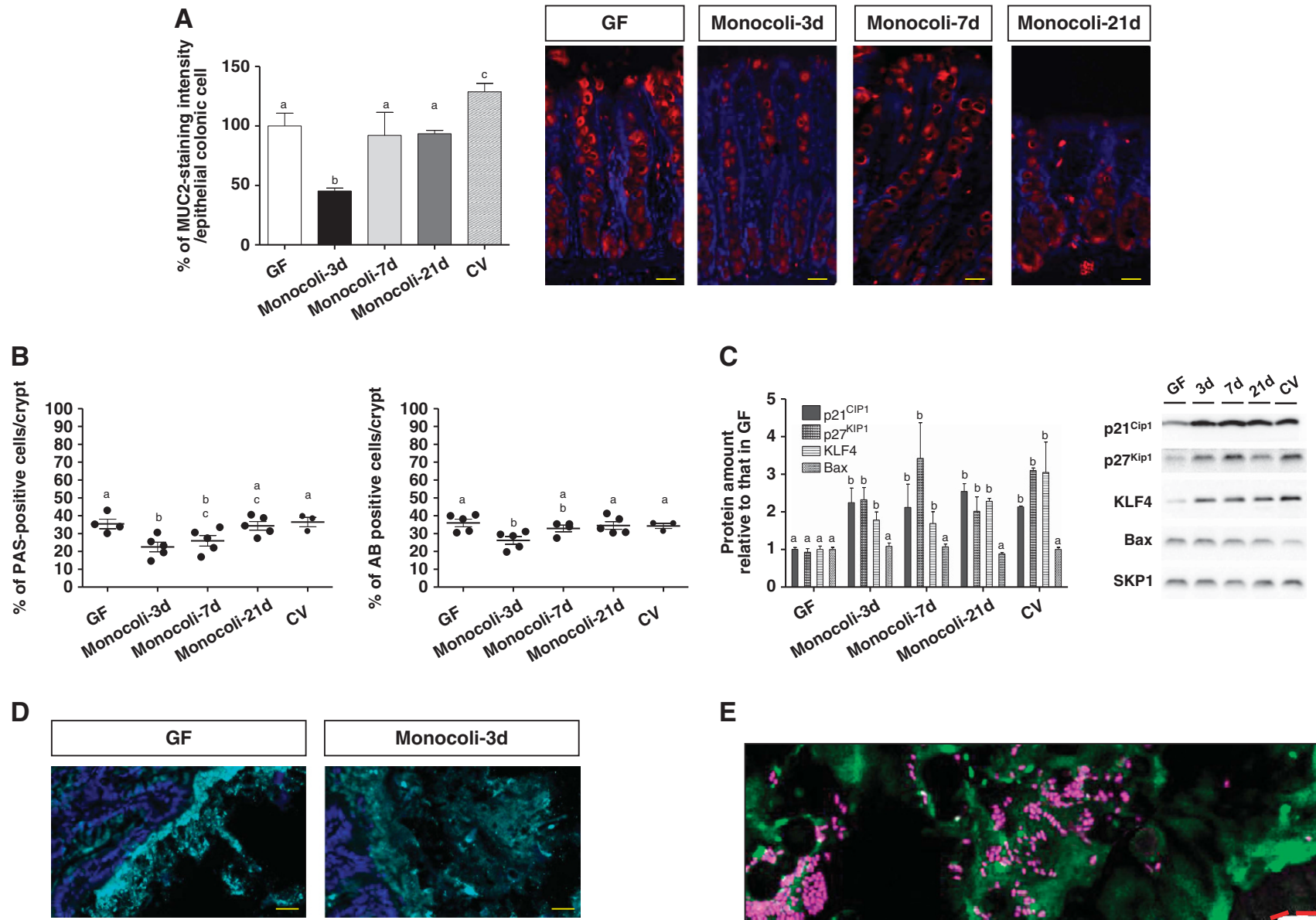

\begin{tabular}{cccccc}
\hline Groups of rats & GF & $\begin{array}{c}\text { Monocoli } \\
-3 d\end{array}$ & $\begin{array}{c}\text { Monocoli- } \\
\text { 7d }\end{array}$ & $\begin{array}{c}\text { Monocoli- } \\
\text { 21d }\end{array}$ & CV \\
\hline $\begin{array}{c}\text { Mucus layer } \\
\text { thickness } \\
(\mu \mathrm{m})\end{array}$ & $129 \pm 65^{\mathrm{a}}$ & $234 \pm 134^{\mathrm{b}}$ & $284 \pm 128^{\mathrm{b}, \mathrm{c}}$ & $296 \pm 112^{\mathrm{b}, \mathrm{c}}$ & $477 \pm 164^{\mathrm{c}}$ \\
\hline
\end{tabular}

E

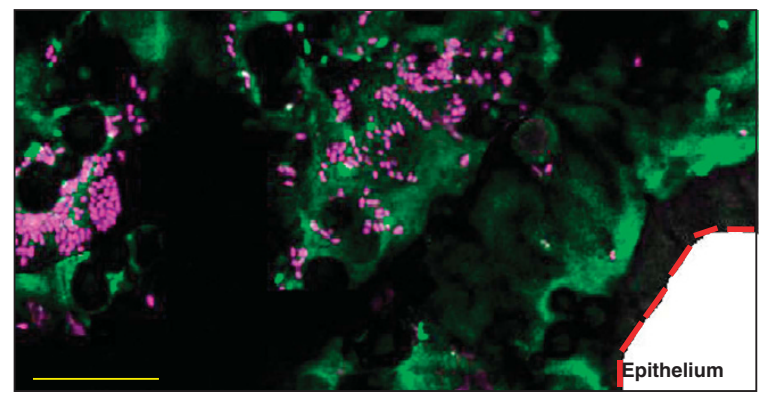

Figure 2 Analyses of the colonic goblet cell population and the mucus layer after inoculation with Escherichia coli CEC15. (A) MUC2-staining intensity/colonic epithelial cell of GF, Monocoli and CV groups $(n=4-6$ per group). Representative images of MUC2 staining with scale bar indicating $50 \mu \mathrm{m}$ for GF and Monocoli groups. See also Supplementary Figure S5A for MUC2 staining by immunohistochemistry. (B) Percentages of PAS- and AB-positive cells/crypt ( $n=4-5$ per group). See Supplementary Figure S5B for representative photographs of PAS staining. (C) Western blot analyses of cell cycle arrest-related proteins (p21 ${ }^{\text {IIP1 }}$ and p27 ${ }^{\text {KIP1P }}$ ), transcription factor KLF4 and the pro-apoptotic protein Bax in colonic epithelial cells isolated from GF, Monocoli and CV groups ( $n=5-7$ per group). SKP1 was used as loading control. For each protein, a representative image and densitometric data are shown. (D) Immunofluorescence staining of MUC2 in unwashed colonic sections from GF, Monocoli and CV groups. Representative images of mucus layer stained with MUC2 in GF and Monocoli rats, after 3 days, with scale bar indicating $50 \mu$ m. Table reporting the thickness of the mucus layer in GF, Monocoli and CV groups ( $n=5-6$ per group). Representative images obtained for Monocoli 7 days and 21 days are shown in Supplementary Figure S5D. (E) FISH analyses with the universal probe Eub338 to detect E. coli CEC15 in unwashed colonic sections of Monocoli 3 days. All values are means \pm s.e.m. Mean values with letter designations are significantly different $(P$-value $<0.05)$.

automated voltage clamp apparatus (DVC 1000; WPI, Hertfordshire, UK). Conductances at $30 \mathrm{~min}$ were calculated according to Ohm's law and paracellular permeability was further assessed by measuring mucosal-to-serosal flux of $4 \mathrm{kDa}$ non metabolizable fluorescein isothiocyanate-labeled dextran (FD4) over $90 \mathrm{~min}$. At the end of the experiment, tissues were challenged with the cholinergic analog carbachol (CCh) on the serosal side $(100 \mu \mathrm{M})$ and $\Delta \mathrm{Isc}$ was recorded.

\section{Statistical analyses}

Data are reported as means \pm s.e.m. Comparisons were performed using $\mathrm{R} \quad 2.13 .0$ software (R Development Core Team, 2005). Kruskal-Wallis (Rcmdr package) and Tukey's range (nparcomp package) tests were used to identify significant differences between groups: if the Kruskal-Wallis test revealed differences, Tukey's range test was used for nonparametric pairwise comparisons to identify groups that were significantly different. 
Mean values annotated with different letters $(\mathrm{a}, \mathrm{b}, \mathrm{c}, \mathrm{d})$ are significantly different $(P<0.05)$.

\section{Results}

Highlight on the prevailing proliferative effects of

E. coli CEC15

$E$. coli is an early colonizer of the gut, reaching high densities within hours after birth (Adlerberth and Wold, 2009). We first monitored the effect of E. coli CEC15 after administration to GF (Monocoli group) using three proliferative markers: PCNA, involved in proliferation and DNA repair; Ki67, widely used as a proliferative marker; and PH3, a mitosis-specific marker. In the Monocoli group, the percentages of PCNA-, Ki67- and PH3-positive cells 3 days post inoculation were higher than in GF, indicating an expansion of the proliferative area in the crypt. These values remained high during the 21 following days, even though they were slightly lower after 21 than 3 days (Figure $1 \mathrm{~A}$ and Supplementary Figure S3A). Twenty-one days post inoculation, the percentage of proliferative cells decreased toward the CV level. In parallel, we observed a substantial, transient, increase of colonic crypt depth 7 days post inoculation reaching the values obtained in CV (Figure 1A and Supplementary Figure S3A). Colonic crypt depth, however, was not maintained 21 days post inoculation with E. coli CEC15. We similarly investigated the effect of one of the other pioneer bacteria, E. faecalis: the percentages of PCNA- and PH3-positive cells, and the crypt depth in Monofaecalis group remained similar to those in the GF (Figure 1B and Supplementary Figure S3B); only Ki67-positive cell count was slightly higher. In the Dicolifaecalis group, the effects of inoculation with the two strains together revealed the prominent effect of $E$. coli CEC15: Ki67-, PCNA- and PH3-positive cell counts were higher than in GF 3 days post inoculation (Figure 1C), and remained high after 21d for Ki67- and PCNA-positive cells; colonic crypt depth also increased transiently. WB analyses of colonic epithelial cells confirmed the proliferation-stimulating effect of $E$. coli CEC15. Cyclin A, a member of the cyclin family required for cell cycle progression, and PCNA were more abundant 3,7 and 21 days post inoculation in Monocoli and Dicolifaecalis groups than in GF group (Figures 1D and F). In Monocoli samples, cyclin A and PCNA amounts tended toward those in CV. The amount of PCNA in the Monofaecalis group was similar to that in GF (Figure 1E).

We evaluated colonization in the three groups: there were $10^{9}$ c.f.u. equivalent per $g$ of cecal content in the Monocoli group and $10^{8}$ in the Monofaecalis group after 21 days (Supplementary Figure S4). In Dicolifaecalis group, the levels of the
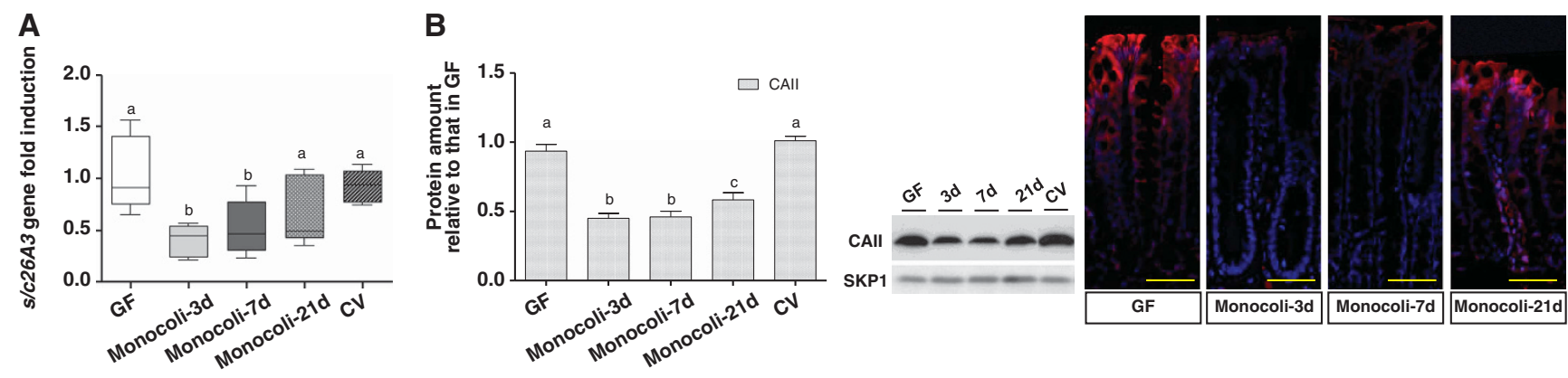

C

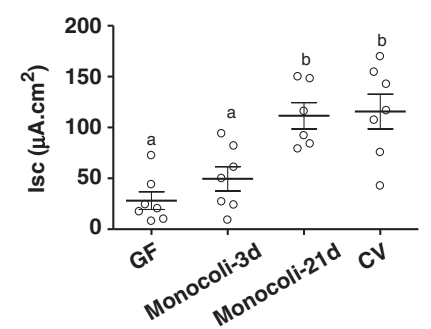

D

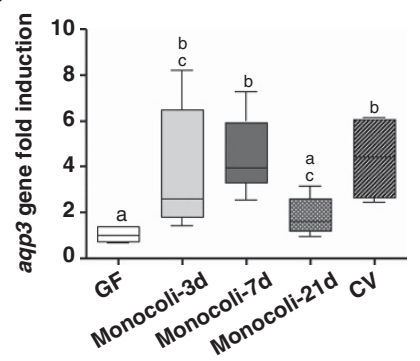

E

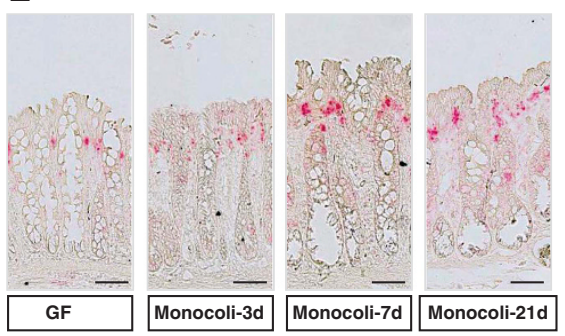

Figure 3 Analyses of colonic ion transporters after inoculation with Escherichia coli CEC15. (A) Relative abundance of slc26A3 mRNA in colonic epithelial cells from GF, Monocoli and CV samples ( $n=5$ per group). Results are normalized to those for 18S rRNA gene expression and compared with values for GF rats. (B) Densitometric analyses and representative western blots for CAII protein performed on colonic epithelial cells isolated from GF, Monocoli and CV samples ( $n=5$ per group), and representative images of immunofluorescence. SKP1 was used as a loading control. (C) Measurement in an Ussing chamber of the short-circuit current ( $\Delta$ Isc) induced after serosal stimulation of colonic tissue with the cholinergic agonist carbachol (CCh). (D) Relative amounts of aqp3 mRNA in colonic epithelial cells of GF, Monocoli and CV groups ( $n=5$ per group). Results are normalized to values for $18 \mathrm{~S}$ rRNA gene expression and compared with values for GF rats. (E) Representative in situ hybridization images of wnt5a in GF and Monocoli groups ( $n=4$ per group). All values are means \pm s.e.m. Mean values with letter designations are significantly different $(P$-value $<0.05)$. Scale bars indicate $50 \mu \mathrm{m}$. 
two bacteria were similar 3 days post inoculation $\left(10^{9}\right.$ c.f.u. equivalent per g of cecal content); the E. coli CEC15 count was stable after 21 days whereas that of E. faecalis CEF15 had declined (Supplementary Figure S4).
E. coli CEC15 elicits a sharp transient remodeling of colonic goblet cell populations and reinforces the mucus barrier.

In parallel to the increase in proliferative markers, we observed that the MUC2-staining intensity was
A

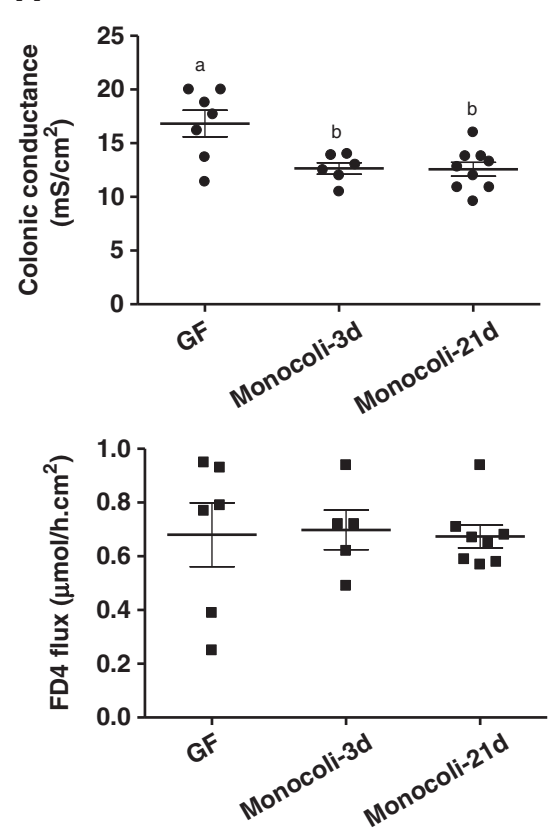

B
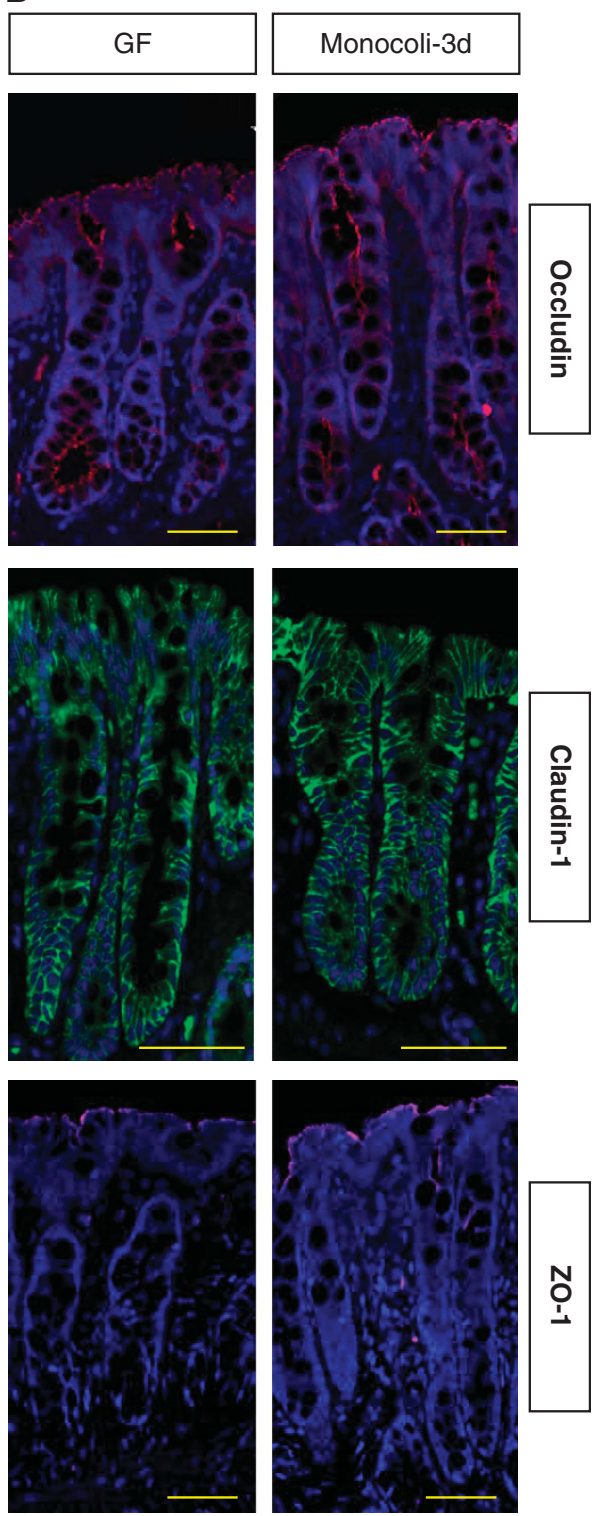

Figure 4 Analyses of the colonic permeability and tight junction proteins in Monocoli groups. (A) Tissue conductance and permeability measurements with $4 \mathrm{kDa}$ FITC-labeled dextran (FD4). Colonic permeability was studied in an Ussing chamber after 30 min (colonic conductance, $\mathrm{mS} \mathrm{cm}^{-2}$ ); paracellular permeability was also assessed for $90 \mathrm{~min}$ by measuring mucosal-to-serosal flux of FD4 ( $\mu \mathrm{mol} \mathrm{h}^{-1}$ $\mathrm{cm}^{2}$ ). (B) Representative immunofluorescence staining for occludin, claudin-1 and ZO-1. As no significant difference was observed between Monocoli-3, -7 and -21d, only one representative photograph of Monocoli-3d is shown. Scale bar indicates $50 \mu \mathrm{m}$.

Figure 5 Analyses of the colonic responses to two defined early colonizing microbiota containing and one not containing Escherichia coli CEC15. EELCF and ELCF groups were both inoculated with E. faecalis CEF15, L. intestinalis CLI15, C. innocuum CCI15 and a novel Fusobacterium spp. CFV15. The EELCF inoculum but not the ELCF inoculum, also contained E. coli CEC15. (A, C) Colonic crypt depth measurements and percentages of PCNA-, Ki67- and PH3-positive cells/crypt in colonic sections from (A) EELCF ( $n=6-9)$ and (C) ELCF $(n=5-7)$ rats. Inoculated rats were killed 3 and 21 days post inoculation. GF and CV rats were used as controls $(n=7-13)$. The right part of the figure shows representative images of immunohistochemistry for Ki67 with the scale bar indicating $50 \mu \mathrm{m}$. (B, D) Western blot analyses of proliferative markers (cyclin A, PCNA) and cell cycle arrest-related proteins ( $221^{\mathrm{CIP} 1}$ and $\mathrm{p} 27^{\mathrm{KIP} 1}$ ) in isolated colonic epithelial cells from (B) EELCF and (D) ELCF groups $(n=4-8)$. Histograms show densitometric values and representative western blots are also presented. SKP1 was used as a loading control. All values are means \pm s.e.m. Mean values with letter designations are significantly different $(P$-value $<0.05)$. 
lower in the Monocoli group than in GF 3 days post inoculation (Figure $2 \mathrm{~A}$ and Supplementary Figure S5A); the staining intensity in the Monocoli group increased thereafter and then remained stable over 21 days but without reaching CV values (Figure 2A and Supplementary Figure S5A).
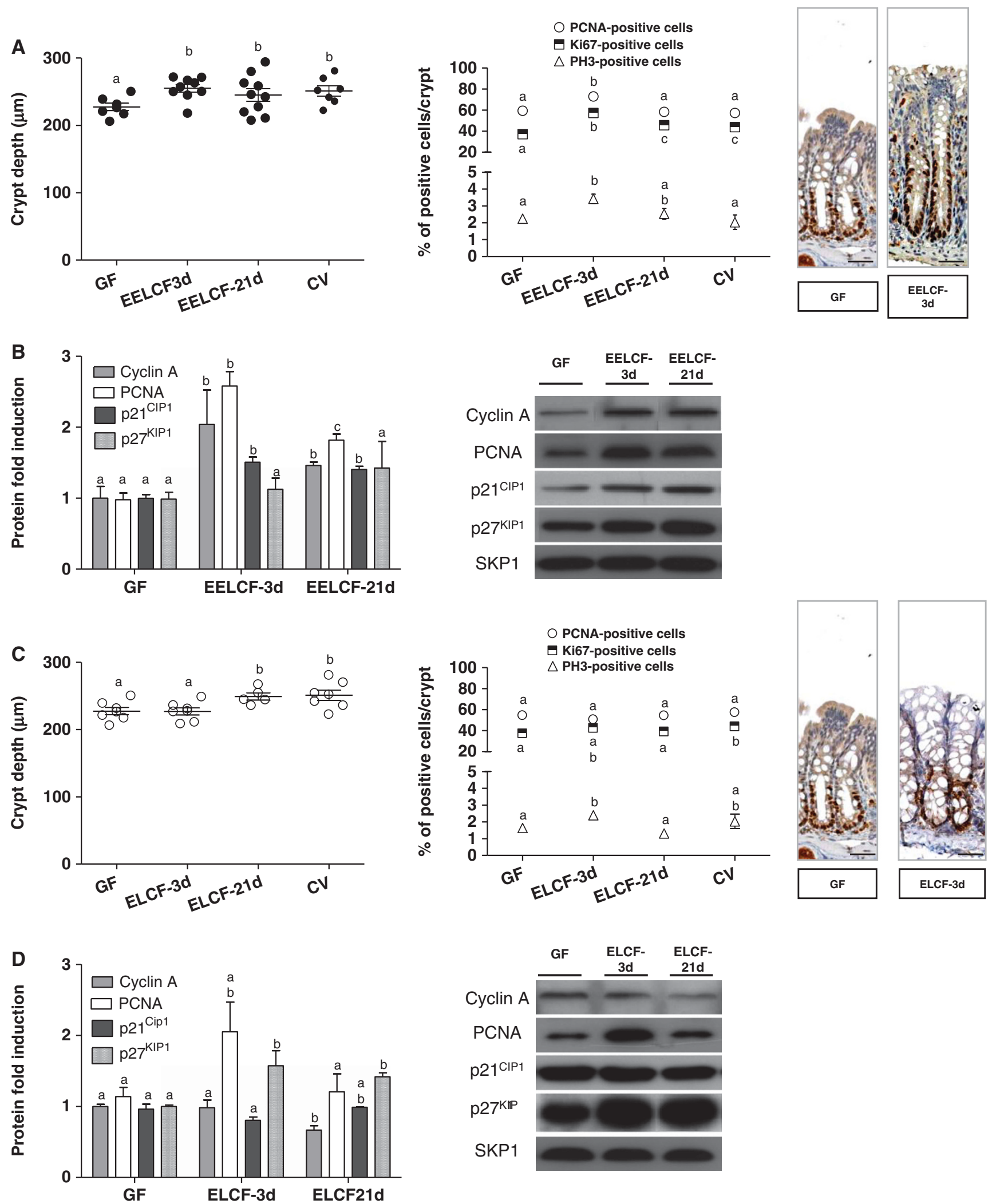
Similarly, the percentages of PAS- and AB-positive cells 3 days post inoculation were below the GF values (Figure 2B); 7 days post inoculation, the number of AB-positive cells increased whereas PASpositive cell counts remained low. By 21 days, the numbers of both PAS- and AB-positive cells were restored to GF and CV values (Figure 2B). Amounts of the two cell cycle arrest-related proteins, p21 ${ }^{\mathrm{CIP} 1}$ and $\mathrm{p} 27^{\mathrm{KIP} 1}$, and the terminal goblet cell transcription factor KLF4, increased from 3 days post inoculation, that is, preceding the restoration of mucus storage in goblet cells and were similar to values for CV rats (Figure 2C). In double labeling experiments, Ki67 labeling and KLF4 labeling were partly superimposed in Monocoli-3d and to a lesser extent in Monocoli-21d whereas they were distinct in GF (Supplementary Figure S5C). The amount of the pro-apoptotic protein Bax was similar whatever the bacterial status of rats (Figure 2C). We performed MUC2 staining of unwashed colonic sections to study the mucus layer. It was twice as thick in the Monocoli group as in GF after 3 days but remained thinner than that in the CV group (Figure 2D). At later stages, 7 days and 21 days post inoculation, the mucus layer converged toward CV values (Figure 2D and Supplementary Figure S5D). FISH and Hoechst analyses indicated that E. coli CEC15 was embedded in the mucus layer from 3 days post inoculation and throughout the 21-day time course (Figure 2E). The numbers of CgA-positive cells also slightly varied in Monocoli group (Supplementary Figure S6). Crypt density was transiently increased: the number of crypts per $\mathrm{mm}$ of colonic section was $12.8 \pm 0.2$ for GF and reached a peak value 7 days post inoculation $(15 \pm 1.2)$.

E. coli CEC15 affects markers of colonic differentiated cells involved in electrolyte and water transport

We tested the effects of E. coli CEC15 on other primary colonic functions. We studied a major $\mathrm{Cl}^{-} / \mathrm{HCO}_{3}^{-}$carrier, Slc26A3, that mediates $\mathrm{Cl}^{-}$ absorption and $\mathrm{HCO}_{3}^{-}$secretion, and CAII that supplies protons and bicarbonate for Slc26A3 (Sterling et al., 2002). Slc26A3 and CAII are localized in differentiated cells at the top of the colonic crypts (Schweinfest et al., 2006). Both slc26A3 gene expression and the amount of CAII protein were lower in the Monocoli group than in GF 3 days and 7 days post inoculation (Figures $3 \mathrm{~A}$ and $\mathrm{B})$. Values tended to increase toward $\mathrm{CV}$ values after 21 days (Figures 3A and B). We also analyzed ion secretion by the colonic epithelium by challenge with the cholinergic agonist CCh (Figure 3C). There was no difference in CCh-induced $\Delta$ Isc between GF and Monocoli rats at $3 \mathrm{~d}$. After 21d, $\Delta$ Isc was higher than in GF and in Monocoli 3 days, and reached CV values. Thus, the shift toward ion secretion under external stimuli is similar in Monocoli rats 3 days post inoculation and GF rats, and is greater in Monocoli rats 21 days post inoculation and CV rats.

We next evaluated the expression of aqp3, a gene encoding a glycerol/water channel. Its pattern of expression was opposite to that of slc26A3 and CAII protein amount. Expression of aqp3 was stronger in Monocoli 3 days than in GF (Figure 3D). By 7 days, it was similar to that in CV rats, but then declined after 21 days (Figure 3D).

We also studied Wnt5a gene expression. The wnt5a gene is expressed in the mesenchyme just beneath the surface of the colonic epithelium; it causes the overlying epithelium to stop proliferating (Miyoshi et al., 2011). In in situ hybridization, Wnt5a staining was stronger in Monocoli-7d and 21d than in Monocoli-3d and GF (Figure 3E) indicating that E. coli CEC15 colonization affected Wnt5a gene expression, which accompanied the related responses of the colonic epithelium to E. coli CEC15 colonization.

\section{E. coli CEC15 preserves the epithelial barrier while} remodeling the colonic epithelium

We tested whether E. coli CEC15 affected colonic epithelial permeability. We obtained contrasting data for conductance and FD4 flux. Colonic epithelial conductance was slightly lower in Monocoli-3d and -21d than in GF, suggesting that the epithelial barrier was reinforced by the presence of E. coli CEC15 (Figure 4A). FD4 flux did not differ between GF and Monocoli groups (Figure 4A). Also tight junction proteins (occludin, claudin-1 and ZO-1) did not differ between groups (Figure 4B). These observations indicate that epithelial barrier integrity is preserved after E. coli CEC15 administration, despite the strong remodeling effect. Data for colonic conductance and staining for tight junction were similar for GF and CV groups (data not shown).

Responses of the colonic epithelium to early colonizing simplified microbiotas differ according to the presence or absence of E. coli CEC15

We investigated the effects of E. coli CEC15 in a more diversified ecosystem. We used defined microbiotas composed of the early colonizing bacteria that we had isolated: $E$. faecalis CEF15, L. intestinalis CLI15, C. innocuum CCI15 and a novel Fusobacterium spp. CFV15 with (EELCF) and without (ELCF) E. coli CEC15. These two simplified microbiotas were used to inoculate GF rats and the presence of inoculated bacterial strains was studied in cecal contents by TTGE analyses and in unwashed colonic sections by FISH (Supplementary Figure S7). The TTGE profiles indicate that all the bacteria were present 3 days post inoculation for both groups and 21 days post inoculation for EELCF. In the ELCF group, Fusobacterium spp. CFV15 was 
hardly detectable 21 days post inoculation (Supplementary Figure S7). In the EELCF group, the E. coli CEC15 count was $10^{9}$ c.f.u. equivalent per $g$ of cecal content both 3 days and 21 days post inoculation. Colonic crypt depth was greater in the EELCF group than in GF and remained similar to the $\mathrm{CV}$ values throughout the 21-day time course (Figure 5A). The percentages of PCNA-, Ki67- and PH3-positive cells were higher in EELCF than in GF 3 days post inoculation but had decreased toward GF and CV values by 21 days (Figure 5A). Similarly, WB analyses showed that the amounts of cyclin A and PCNA in the colon, like the amounts of $\mathrm{p} 21^{\mathrm{CIP} 1}$, were higher in EELCF than in GF (Figure 5B). The colonic responses to the mix without $E$. coli CEC15 differed in that the increase in colonic crypt depth was delayed. Indeed, an increase in colonic crypt depth similar to that of the EELCF and CV group was observed in the ELCF group not at 3 days but at 21 days post inoculation (Figure 5C). Moreover, the increase in colonic epithelial cell proliferation was strongly attenuated: PH3-positive cell numbers in ELCF-3d increased above GF values but were significantly lower than those observed for EELCF-3d rats (Figure 5C). Furthermore, the percentages of PCNA- and Ki67-positive cells, and cyclin A protein amounts were similar to GF and lower than EELCF-3d rats (Figures 5C and D). Also p21 $1^{\mathrm{CIP} 1}$ protein amount remained low in ELCF rats relative to EELCF-3d rats (Figure 5D). However, in colonic epithelial cells isolated from ELCF-3d rats, the amount of PCNA protein increased, similar to that in EELCF and in p27 ${ }^{\mathrm{KIP} 1}$, slightly more than in EELCF (Figure 5D). All together, these data revealed that colonic epithelial cells responded differently to ELCF and EELCF.

\section{Discussion}

Regulation of the eukaryotic cell cycle by E. coli has been mostly studied in a context of pathogenesis. Some E. coli strains, including those residing in the human gut, produce bacterial toxins including colibactin, which modulate the eukaryotic cell cycle (Nougayrede et al., 2006) and can trigger genomic instability in mammalian cells (CuevasRamos et al., 2010). A strong association is observed between colon tumor development and the colonization of the mucosa by E. coli strains harboring genes encoding colibactin (Arthur et al., 2012). Interestingly, these bacterial effectors are not only associated with deleterious effects, as colibactin also supports the probiotic effects of $E$. coli Nissle 1917 (Olier et al., 2012).

We identified an early colonizing strain of $E$. coli as a substantial player in remodeling of the colonic epithelium and suggest that this interaction could be a first step in the establishment of a microbiota-compliant state. Monocolonization with E. coli CEC15 stimulated colonic epithelial proliferation whereas the other early colonizer, E. faecalis CEF15, did not. However, counts of colonizing $E$. faecalis CEF15 were 10-fold lower than those of $E$. coli CEC15 such that we cannot rule out the possibility that bacterial cell density could also be an important driver of host cell proliferation. In the presence of E. coli, the colonic crypts were poorly differentiated in the early phase post-colonization, but then differentiated cell markers (mucins, and ion and water transporters) converged progressively toward CV levels. Experiments with defined mixes composed of the other isolated bacteria revealed that the colonic epithelium responses differed according to whether or not E. coli CEC15 was present. As our experimental model involved adult rats, we showed this mechanism operates on epithelium that is mature, but naive in terms of exposure to microorganisms, which is similar to the situation in newborn humans.

Regulation of the eukaryotic cell cycle by commensal bacteria has frequently been described but its relevance to homeostatic relationships remains unclear. The stimulation of intestinal epithelial cell proliferation by commensal bacteria may be beneficial to the host. In mice, the recognition of commensal bacterial by Toll-like receptors initiates the colonic epithelial proliferation required for repair after epithelial injury (Pull et al., 2005). We previously observed a transient expansion of the proliferative area after conventionalization with complex microbiotas, followed by a progressive return toward the homeostatic state of CV (Cherbuy et al., 2010; Tomas et al., 2013). This is accompanied by an increase in the colonic crypt depth. We report a similar pattern here, both when $E$. coli was inoculated alone or in combination with other bacteria. However, E. coli CEC15 inoculated alone did not fully mimic the conventionalization pattern: the increase in colonic crypt depth was not maintained suggesting that inoculation of $E$. coli alone is not sufficient to counterbalance the epithelial atrophy in GF rats.

Goblet cells were transiently altered in the Monocoli group. E. coli CEC15 administration was followed by a rapid decrease in epithelial MUC2 and mucopolysaccharide contents, and presumably these components are released to join the mucus layer, the thickness of which doubled $3 \mathrm{~d}$ post inoculation. The epithelial cells then rapidly refilled with MUC2 and acidic mucopolysaccharides, whereas it took more time for neutral mucopolysaccharides to recover to the levels seen in GF and CV. E. coli CEC15 was found embedded in the mucus layer, consistent with intestinal colonization by commensal E. coli being dependent on its ability to grow in mucus. Studies in vitro and in vivo with mono-associated mouse models reveal that commensal E. coli can grow on monosaccharides derived from mucins (Chang et al., 2004; Alpert et al., 2009). In contrast, strains of E. coli unable to 
survive in mucus fail to colonize the intestine (Moller et al., 2003; Chang et al., 2004). The occupation of nutritional niches by a mix of commensal E. coli strains prevents colonization by pathogenic E. coli, revealing the importance of pre-colonization by commensals for protection against pathogens (Maltby et al., 2013). However, this effect does not seem to be restricted to E. coli, as two major representative bacteria of the human gut microbiota modify both goblet cells and the glycosylation profile (Wrzosek et al., 2013).

The proteins Slc26A3 and CA are essential for $\mathrm{Cl}^{-}$ and $\mathrm{HCO}_{3}^{-}$homeostasis (Höglund et al., 1996). Both slc26A3 expression and CAII protein abundance varied similarly after $E$. coli CEC15 administration and inversely to the expansion of the proliferative compartment. Thus, loss of differentiated cells and the associated increase in the number of proliferative cells may have consequences for ion fluxes. The effect of CCh was similar 3 days post inoculation as in GF, indicating that the capacity to shift toward ion secretion under external stimuli was unaffected during the early phase of colonization. $\mathrm{Cl}^{-}$secretion and the resultant fluid transport are thought to be an innate defense mechanism in the intestine to flush out enteric pathogens. However, this mechanism can also target commensal bacteria as it has a selective effect on gut bacterial communities (Keely et al., 2012). In our model, this mechanism only started to be established late postinoculation concomitantly with the increase in slc26A3 expression and CAII protein abundance. Possibly, the low ion secretion capacity early after E. coli administration may create a favorable environment for colonization. In contrast to slc26A3 and CAII, the expression of the aqp3 gene was enhanced from 3-day post-inoculation and thus paralleled proliferation. Deletion of aqp3 leads to impaired colonic cell proliferation in a colitis model (Thiagarajah et al., 2007), whereas deletion of slc26A3 leads to enhanced colonic proliferative activity (Schweinfest et al., 2006). Thus, the effects of E. coli CEC15 on ion transporters are coherent with their functions in cell proliferation. An increase in Wnt5a gene expression accompanied the responses of the colonic epithelium to $E$. coli CEC15. A recent study implicates Wnt5a in the bacterial epithelial cross talk contributing to the regulation of intestinal homeostasis: Wnt5a is weakly expressed in the colon of mice lacking commensal bacteria, whereas colonic Wnt5a expression is increased by conventionalization of GF mice (Neumann et al., 2014).

Citrobacter rodentium infection, which mimics E. coli enteric infections in mice, leads to a highly proliferative and poorly differentiated colonic epithelium due to the downregulation of slc26A3 and CAIV, (another member of the CA family) (Papapietro et al., 2013). Thus, pathogenic and commensal bacteria modulate common targets; however, this process is worsened with pathogenic bacteria, whereas it is balanced with commensal strains with the progressive induction of $\mathrm{p} 21^{\mathrm{CIP} 1}$ and p27 ${ }^{\mathrm{KIP} 1}$, and Wnt5a. The remodeling effect of E. coli CEC15 also preserved epithelial barrier, unlike pathogenic strains of E. coli (Denizot et al., 2012). Neither microscopic colonic damage, nor diarrhea, nor weight loss were observed in rats after $E$. coli CEC15 administration (data not shown). The values for slc26A3 and aqp3 gene expression, CAII protein amounts and $\Delta$ Isc after CCh stimulation were in the range of, or below, physiological values (those in $\mathrm{CV}$ rats).

E. coli is one of the first bacterial species to colonize the intestine and remains the predominant aerobic organism in the gastrointestinal tract in adulthood (Tenaillon et al., 2010). The pattern of colonization of the gut by $E$. coli has been changing substantially over recent decades (Nowrouzian et al., 2003; Azad et al., 2013), probably due to modern lifestyles (Adlerberth et al., 2006; Blaser and Falkow, 2009). The prevalence of phylogenetic groups of $E$. coli is changing and this may have consequences for the host's health (Cuevas-Ramos et al., 2010).

Our work shows that commensal early colonizing E. coli drives remodeling of the colonic epithelium affecting the structure of the epithelium, the mucus layer, and ion and water transport in rats without affecting the integrity of epithelium. Early colonizing $E$. coli is clearly highly significant, and may facilitate the establishment of favorable microenvironment for commensal colonization.

\section{Conflict of Interest}

The authors declare no conflict of interest.

\section{Acknowledgements}

We thank Muriel Mercier-Bonin for fruitful discussions and critical reading of the manuscript, the Animalerie Axénique de MICALIS (ANAXEM) platform (Microbiologie de l'Alimentation au Service de la Santé (MICALIS), Jouy-en-Josas, France) for animal facilities, Abdelhak Boukadiri for help with histology, Thierry Pedron and Céline Mulet for help with PAS staining, Lydie Venteo for HIS training, Pierre Adenot for access to the Zeiss Apotome, MIMA2 platform, INRA, Jouy-en-Josas, and Philippe Gérard, Pascal Bally and Aurelia Bruneau for help with TTGE and FISH experiments. JT was the recipient of a Contrat Jeune Scientifique from the Institut National de la Recherche Agronomique (Jouy-en-Josas, France).

\section{References}

Adlerberth I, Lindberg E, Aberg N, Hesselmar B, Saalman R, Strannegard IL et al. (2006). Reduced enterobacterial and increased staphylococcal colonization of the infantile bowel: an effect of hygienic lifestyle? Pediatr Res 59: 96-101. 
Adlerberth I, Wold AE. (2009). Establishment of the gut microbiota in Western infants. Acta Paediatr 98: 229-238.

Alper C, Scheel J, Enges W, Loh G, Bliaut M. (2009). Adaptation of protéine expression by Escherichia coli in the gastro-intestinal tract of gnotobiotic mice. Environ Microbiol 11: 751-761.

Arthur JC, Perez-Chanona E, Muhlbauer M, Tomkovich S, Uronis JM, Fan TJ et al. (2012). Intestinal inflammation targets cancer-inducing activity of the microbiota. Science 338: 120-123.

Azad MB, Konya T, Maughan H, Guttman DS, Field CJ, Chari RS et al. (2013). Gut microbiota of healthy Canadian infants: profiles by mode of delivery and infant diet at 4 months. CMAJ: Can Med Assoc J 185: 385-394.

Blaser MJ, Falkow S. (2009). What are the consequences of the disappearing human microbiota? nature reviews. Microbiology 7: 887-894.

Brown EM, Sadarangani M, Finlay BB. (2013). The role of the immune system in governing host-microbe interactions in the intestine. Nat Immunol 14: 660-667.

Chang DE, Smalley DJ, Tucker DL, Leatham MP, Norris WE, Stevenson SJ et al. (2004). Carbon nutrition of Escherichia coli in the mouse intestine. Proc Natl Acad Sci USA 101: 7427-7432.

Cherbuy C, Darcy-Vrillon B, Morel MT, Pégorier JP, Duée PH. (1995). Effect of germfree state on the capacities of isolated rat colonocytes to metabolize n-butyrate, glucose, and glutamine. Gastroenterology 109: 1890-1899.

Cherbuy C, Honvo-Houeto E, Bruneau A, Bridonneau C, Mayeur C, Duée PH et al. (2010). Microbiota matures colonic epithelium through a coordinated induction of cell cycle-related proteins in gnotobiotic rat. Am J Physiol Gastrointest Liver Physiol 299: G348-G357.

Cuevas-Ramos G, Petita CR, Marcq I, Boury M, Oswald E, Nougayrède JP. (2010). Escherichia coli induces DNA damage in vivo and triggers genomic instability in mammalian cells. PNAS 105: 11537-11542.

Denizot J, Sivignon A, Barreau F, Darcha C, Chan HF, Stanners CP et al. (2012). Adherent-invasive Escherichia coli induce claudin-2 expression and barrier defect in CEABAC10 mice and Crohn's disease patients. Inflamm Bowel Dis 18: 294-304.

Dominguez-Bello MG, Costello EK, Contreras $M$, Magris M, Hidalgo G, Fierer N et al. (2010). Delivery mode shapes the acquisition and structure of the initial microbiota across multiple body habitats in newborns. Proc Natl Acad Sci USA 107: 11971-11975.

Drozdowski LA, Clandinin T, Thomson AB. (2010). Ontogeny, growth and development of the small intestine: understanding pediatric gastroenterology. World J Gastroenterol 16: 787-799.

Ducroc R, Garzon B, Geloso JP, Hervatin F, Millet PH, Moreau E. (1988). Development of sodium and chloride transport across fetal and newborn rat stomach in vitro. J Physiol 398: 543-554.

El Aidy S, van Baarlen P, Derrien M, Lindenbergh-Kortleve DJ, Hooiveld G, Levenez F et al. (2012). Temporal and spatial interplay of microbiota and intestinal mucosa drive establishment of immune homeostasis in conventionalized mice. Mucosal Immunol 5: 567-579.

Gerard P, Beguet F, Lepercq P, Rigottier-Gois L, Rochet V, Andrieux C et al. (2004). Gnotobiotic rats harboring human intestinal microbiota as a model for studying cholesterol-to-coprostanol conversion. FEMS Microbiol Ecol 47: 337-343.
Höglund P, Haila S, Socha J, Tomaszewski L, Saarialho-Kere U, Karjalainen-Lindsberg $\mathrm{M}$ et al. (1996). Mutations of the down-regulated in adenoma (DRA) gene cause congenital chloride diarrhoea. Nat Genet 14: 316-319.

Hooper L, Macpherson A. (2010). Immune adaptations that maintain homeostasis with the intestinal microbiota. Nat Rev Immunol 10: 159-169.

Keely S, Kelly CJ, Weissmueller T, Burgess A, Wagner BD, Robertson CE et al. (2012). Activated fluid transport regulates bacterial-epithelial interactions and significantly shifts the murine colonic microbiome. Gut Microbes 3: 250-260.

Koenig JE, Spor A, Scalfone N, Fricker AD, Stombaugh J, Knight $\mathrm{R}$ et al. (2011). Succession of microbial consortia in the developing infant gut microbiome. PNAS 108: 4578-4585.

Livak KJ, Schmittgen TD. (2001). Analysis of relative gene expression data using real-time quantitative PCR and the 2-DDCT method. Methods 25: 402-408.

Maltby R, Leatham-Jensen MP, Gibson T, Cohen PS, Conway T. (2013). Nutritional basis for colonization resistance by human commensal Escherichia coli strains HS and Nissle 1917 against E. coli O157:H7 in the mouse intestine. PLoS One 8: e53957.

Miyoshi H, Ajima R, Luo CT, Yamaguchi TP, Stappenbeck TS. (2011). Wnt5a potentiates TGF- $\beta$ signaling to promote colonic crypt regeneration after tissue injury. Science 338: 108-112.

Moller AK, Leatham MP, Conway T, Nuijten PJM, de Haan LAM, Krogfelt KA et al. (2003). An Escherichia coli MG1655 lipopolysaccharide deeprough core mutant grows and survives in mouse cecal mucus but fails to colonize the mouse large intestine. Infect Immun 71: 2142-2152.

Neumann PA, Koch S, Hilgarth RS, Perez-Chanona E, Denning P, Jobin C et al. (2014). Gut commensal bacteria and regional wnt gene expression in the proximal versus distal colon. Am J Pathol 184: 592-599.

Nougayrede JP, Homburg S, Taieb F, Boury M, Brzuszkiewicz E, Gottschalk G et al. (2006). Escherichia coli induces DNA double-strand breaks in eukaryotic cells. Science 313: 848-851.

Nowrouzian F, Hesselmar B, Saalman R, Strannegard IL, Aberg N, Wold AE et al. (2003). Escherichia coli in infants' intestinal microflora: colonization rate, strain turnover, and virulence gene carriage. Pediatr Res 54: 8-14.

Olier M, Marcq I, Salvador-Cartier C, Secher T, Dobrindt U, Boury M et al. (2012). Genotoxicity of Escherichia coli Nissle 1917 strain cannot be dissociated from its probiotic activity. Gut Microbes 3: 501-509.

Olszak T, An D, Zeissig S, Vera M, Richter J, Franke A et al. (2012). Microbial exposure during early life has persistent effects on natural killer $\mathrm{T}$ cell function. Science 336: 489-493.

Palmer C, Bik EM, DiGiulio DB, Relman DA, Brown PO. (2007). Development of the human infant intestinal microbiota. PLOS Biol 5: e177.

Papapietro O, Teatero S, Thanabalasuriar A, Yuki KE, Diez E, Zhu L et al. (2013). R-spondin 2 signalling mediates susceptibility to fatal infectious diarrhoea. Nat Commun 4: 1898.

Puiman P, Stoll B. (2008). Animal models to study neonatal nutrition in humans. Curr Opin Clin Nutr Metab Care 11: 601-606. 
Pull SL, Doherty JM, Mills JC, Gordon JI, Stappenbeck TS. (2005). Activated macrophages are an adaptive element of the colonic epithelial progenitor niche necessary for regenerative responses to injury. Proc Natl Acad Sci USA 102: 99-104.

R Development Core Team. (2005). R: a language and environment for statistical computing. R Foundation for Statistical Computing: Vienna, Austria. http:// www.R-project.org.

Rochet V, Rigottier-Gois L, Rabot S, Doré J. (2004). Validation of fluorescent in situ hybridization combined with flow cytometry for assessing interindividual variation in the composition of human fecal microflora during long-term storage of samples. J Microbiol Methods 59: 263-270.

Rul F, Ben-Yahia L, Chegdani F, Wrzosek L, Thomas S, Noordine ML et al. (2011). Impact of the metabolic activity of Streptococcus thermophilus on the colon epithelium of gnotobiotic rats. $J$ Biol Chem 286: 10288-10296.

Russell S, Gold M, Hartmann M, Willing B, Thorson L, Wlodarska $\mathrm{M}$ et al. (2012). Early life antibioticdriven changes in microbiota enhance susceptibility to allergic asthma. EMBO Rep 13: 440-447.

Schluter J, Foster K. (2012). The evolution of mutualism in gut microbiota via host epithelial selection. PLoS Biol 10: e1001424.

Schweinfest CW, Spyropoulos DD, Henderson KW, Kim JH, Chapman JM, Barone S et al. (2006). slc26a3 (dra)-deficient mice display chloride-losing diarrhea, enhanced colonic proliferation, and distinct up-regulation of ion transporters in the colon. $J$ Biol Chem 281: 37962-37971.

Sterling D, Brown NJ, Supuran CT, Casey JR. (2002). The functional and physical relationship between the
DRA bicarbonate transporter and carbonic anhydrase II. Am J Physiol Cell Physiol 283: C1522-C1529.

Tenaillon O, Skurnik D, Picard B, Denamur E. (2010). The population genetics of commensal Escherichia coli. Nat Rev Microbiol 8: 207-217.

Thiagarajah JR, Zhao D, Verkman AS. (2007). Impaired enterocyte proliferation in aquaporin-3 deficiency in mouse models of colitis. Gut 56: 1529-1535.

Thomas M, Wrzosek L, Ben-Yahia L, Noordine ML, Gitton C, Chevret D et al. (2011). Carbohydrate metabolism is essential for the colonization of Streptococcus thermophilus in the digestive tract of gnotobiotic rats. PLoS One 6: e28789.

Tomas J, Wrzosek L, Bouznad N, Bouet S, Mayeur C, Noordine ML et al. (2013). Primocolonization is associated with colonic epithelial maturation during conventionalization. FASEB J 27: 645-655.

Turturro A, Witt WW, Lewis S, Hass BS, Lipman RD, Hart RW. (1999). Growth curves and survival characteristics of the animals used in the biomarkers of aging program. J Gerontol: Biol Sci 54: B492-B501.

Van der Flier LG, Clevers H. (2009). Stem cells, self-renewal, and differentiation in the intestinal epithelium. Ann Rev Physiol 71: 241-260.

Wrzosek L, Miquel S, Noordine ML, Bouet S, Chevalier-Curt MJ, Robert V et al. (2013). Bacteroides thetaiotaomicron and Faecalibacterium prausnitzii influence the production of mucus glycans and the development of goblet cells in the colonic epithelium of a gnotobiotic model rodent. BMC Biol 11: 61.

Yatsunenko T, Rey FE, Manary MJ, Trehan I, Dominguez-Bello MG, Contreras M et al. (2012). Human gut microbiome viewed across age and geography. Nature 486: 222-227.

Supplementary Information accompanies this paper on The ISME Journal website (http://www.nature.com/ismej) 